\title{
Entre a castração e a sutura: a aposta de Pascal na construção do caso clínico ${ }^{1}$
}

Paulo Alberto Teixeira Bueno

\begin{abstract}
Resumo
Neste trabalho, apresentaremos o relato de um caso clínico articulado com a noção de aposta. Pascal elegeu esse termo como pilar argumentativo de suas proposições acerca da existência de Deus. A premissa é a de que o sujeito não pode se esquivar da escolha sobre a existência divina, logo a aposta se torna imperativa. Desse modo, algo se perde necessariamente, posto que em todo jogo algo precisa ser apostado, e é precisamente isso - que se aposta - o que se perde. O caso será o de uma paciente cujo filho nasceu com uma malformação genital, apresentando os órgãos sexuais feminino e masculino. A criança estava prestes a ser submetida a uma cirurgia definitiva, em que um dos órgãos sexuais seria castrado, no real. A decisão sobre a cirurgia teria de ser tomada por essa mãe, que vacilava, e durante o processo analítico operaram-se alguns giros em sua posição discursiva que mudou o destino da criança. Recorreremos às elaborações contidas no Seminário 16, em que Lacan retoma a aposta de Pascal para avançar na formalização da inconsistência no campo do Outro, e delas buscaremos extrair consequências clínicas.
\end{abstract}

\section{Palavras-chave:}

Castração; Aposta de Pascal; Gênero.

\section{Between castration and the suture: Pascal's bet in the construction of the clinical case}

\begin{abstract}
We will present in this work the report of a clinical case articulated with the notion of bet. Pascal chose this term as an argumentative pillar of his propositions

10 presente artigo é uma versão ampliada da apresentação realizada no II Simpósio Interamericano da Internacional dos Fóruns do Campo Lacaniano e no XVII Encontro Nacional da EPFCL-Brasil — Sexuação e Identidades, realizados em setembro de 2017.
\end{abstract}


about the existence of God. The premise is that the subject cannot dodge the choice of divine existence, so the bet becomes imperative. In this way something is necessarily lost, since in every game something needs to be bet and it is precisely this - which is bet - what is lost. The case will be that of a patient whose child was born with a genital malformation, having the female and male sex organs. The child was about to undergo a definitive surgery in which one of the sex organs would be castrated, in the real. The decision about the surgery would have to be taken by this mother, who hesitated, and during the analytical process operated a few turns in her discursive position that changed the destiny of the child. We will turn to the elaborations contained in Seminar 16 - in which Lacan takes up Pascal's bet in order to advance upon the formalization of the inconsistency in the field of the Other - and from them we seek to extract clinical consequences.

\title{
Keywords:
}

Castration; Pascal's bet; Genre.

\section{Entre la castración y la sutura: la apuesta de Pascal en la construcción del caso clínico}

\begin{abstract}
Resumen
Presentaremos en este trabajo el relato de un caso clínico articulado a la noción de apuesta. Pascal eligió este término como eje argumentativo de sus proposiciones acerca de la existencia de Dios. La premisa es que el sujeto no puede esquivar la elección sobre la existencia divina, luego la apuesta se vuelve imperativa. De este modo, algo se pierde necesariamente, puesto que en todo juego algo necesita ser apostado y es precisamente esto - que se apuesta - lo que se pierde. El caso será el de una paciente cuyo hijo nació con una malformación genital, con los órganos sexuales femenino y masculino. El niño estaba a punto de someterse a una cirugía definitiva en la que uno de los órganos sexuales sería castrado, en lo real. La decisión sobre la cirugía tendría que ser tomada por esa madre, que vacilaba, y durante el proceso analítico se operó algunos giros en su posición discursiva que cambió el destino del niño. Recurriremos a las elaboraciones contenidas en el Seminario 16 - en que Lacan retoma la apuesta de Pascal para avanzar en la formalización de la inconsistencia en el campo del Otro - y de ellas buscaremos extraer consecuencias clínicas..
\end{abstract}

\section{Palabras clave:}

Castración; Apuesta de Pascal; Género. 


\title{
Entre castration et suture: \\ Le pari de Pascal dans la construction du cas clinique
}

\begin{abstract}
Résumé
Nous présenterons dans ce travail un cas clinique articulé avec la notion de pari. Pascal a choisi ce terme comme un pilier argumentatif de ses propositions sur l'existence de Dieu. La prémisse, c'est que le sujet ne peut pas éviter le choix de l'existence divine, de sorte que le pari devient impératif. Ainsi, quelque chose se perd forcément, puisque dans chaque jeu quelque chose doit être parié, et c'est justement cela, c'est-à-dire ce qu'on pari, ce qu'on perd. On traitera du cas d'une patiente dont l'enfant est né avec une malformation génitale, ayant les organes sexuels féminins et masculins. L'enfant était sur le point de subir une intervention chirurgicale définitive, dans laquelle l'un des organes sexuels serait castré, dans le réel. La décision à propos de l'opération devait être prise par cette mère, qui hésitait, et au cours du processus analytique quelques tours dans sa position discursive ont eu lieu, ce qui a changé le destin de l'enfant. Nous ferons appel à des élaborations présentes dans le Séminaire 16, dans lequel Lacan reprend Pascal pour faire avancer dans la formalisation de l'inconsistance du champ de l'Autre, et on cherchera à en extraire les conséquences cliniques.
\end{abstract}

\section{Mots-clés:}

Castration; Pari de Pascal; Genre.

\section{Introdução}

Buscamos, com o presente texto, realizar a exposição de um caso clínico, articulando-o com alguns apontamentos que Lacan faz acerca da aposta de Pascal. À época do atendimento, G. tinha 1 ano e 3 meses de idade. Foi encaminhado ao Centro de Atenção Psicossocial Infantojuvenil (CAPSij) para avaliação por sua pediatra com hipótese diagnóstica de "distúrbio do comportamento", como escrevera no encaminhamento. A criança apresentava-se excessivamente agitada, com alteração no sono, e os pais desconfiavam que havia atraso em seu desenvolvimento. Houve duas sessões de avaliação, a partir das quais deveria ser decidido se ela seria atendida no CAPSij. Não foram constatadas questões significativas no que tange à estruturação subjetiva ou outras que justificassem sua permanência no CAPSij, e o fato de ela já ser acompanhado na Unidade Básica de Saúde (UBS) por psicóloga e fonoaudióloga auxiliou para que a indicação fosse a de manutenção dos atendimentos na referida UBS.

Algo no decorrer das entrevistas de avaliação, entretanto, chamou a atenção: todas as ultrassonografias que Ângela (nome fictício), sua mãe, realizou durante a 
gestação acusaram que seria uma menina. Porém, quando do nascimento, os pais foram surpreendidos: G. nasceu com uma raríssima malformação genital, tendo o órgão sexual feminino e também o masculino, este atrofiado. Essa malformação, também conhecida como genitália ambígua, se define como uma condição em que o órgão não oferece condições de caracterizar o sexo do bebê. Os exames genéticos iniciais descartaram a hipótese de hermafroditismo verdadeiro, mas foram inconclusos na definição do sexo de G. A mãe, que sempre sonhou com uma menina e que criara muitas expectativas em torno da filha esperada, entrou em depressão após o nascimento da criança. G. foi vestido com o enxoval da filha gestada - mas nunca nascida - durante seus seis primeiros meses. Nessa época, após uma bateria de exames, foi anunciado que G. era um menino. A indicação da equipe médica foi a de que se realizasse uma cirurgia de redesignação sexual. Embora esse procedimento cirúrgico seja mais conhecido por sua aplicação em pessoas transexuais, na retirada do órgão ou na criação de neopênis e neovaginas, não se restringe a esse público. Define-se como a alteração cirúrgica de características sexuais de nascença. A intervenção, nesse caso, seria a de extrair o órgão feminino, o que ocorreria após alguns meses de aplicação de hormônios masculinos.

Os pais, naquele instante, estavam à espera da cirurgia, que seria realizada em dois meses. Apesar de não ter sido apresentada como sendo deles — os pais perguntei sobre o que sentiam diante daquela decisão, ao que a mãe respondeu: "O que dá uma segurança é o fato dos exames terem confirmado que G. é um menino." Ao falar isso, chorou, e todas as vezes que o assunto era a operação, vacilava. A intervenção do analista de indicar que a operação era uma decisão a ser tomada por eles, ao que parece, produziu efeitos em Ângela e ressituou - para ela - a questão. Antes, o que imperava era a palavra médica: “é um menino, há de se fazer a cirurgia". Sua vacilação revelou que ali havia uma demanda para além da preocupação sobre o sono e a agitação do garoto; revelavam-se ali um impasse e a posição de um sujeito perante uma decisão.

\section{A aposta de Pascal}

Pascal, em seu fragmento Infinito nada, apresenta aquilo que ficou conhecido como sua aposta e que pode ser lida como uma estrutura decisória. Basicamente, trata-se de apostar ou não na existência de Deus. A primeira questão com a qual se depara é sobre a possibilidade de dar fé em algo cuja natureza lhe é desconhecida; de afirmar a existência daquilo que não se sabe o que é. Para desenvolver o problema, o filósofo lança mão de uma articulação entre a problemática da existência divina com as noções matemáticas de finitude e infinito.

Da finitude, conhecemos sua natureza e extensão, e isso é possível porque somos também finitos e extensos. Há também, por outro lado, o infinito, do qual desconhecemos sua natureza. $\mathrm{O}$ fato de ignorar-se o que é o infinito não invalida 
que se afirme sua existência. Há o infinito: "como sabemos que é falso que os números sejam finitos, logo é verdade que há um infinito em número. Mas não sabemos o que ele é" (Pascal, 1670/1961, p. 109). Na mesma linha, pode-se inferir que Deus existe, embora não se saiba nada acerca de sua natureza. É a partir do caráter apodítico da noção matemática que afirma a existência e a inapreensibilidade racional do infinito que o filósofo traça uma linha homológica com Deus: “Pode-se, pois, reconhecer que há um Deus sem saber o que é” (Pascal, 1670/1961, p. 109). Esse passo é essencial para a construção do liame argumentativo da aposta, vejamos por quê:

A unidade acrescentada ao infinito em nada o aumenta, como não aumenta uma medida infinita um pé que a ela se acrescente. $\mathrm{O}$ finito se aniquila na presença do infinito, e torna-se um puro nada. Assim, nosso espírito em face de Deus; assim nossa justiça em face da justiça divina. Não há uma desproporção tão grande entre a nossa justiça e a de Deus, como entre unidade e infinito. (Pascal, 1670/1961, p. 108)

Essa definição matemática ganha em importância por afirmar que qualquer inteiro somado ao infinito em nada altera o produto da operação. Em outras palavras, há a anulação da unidade diante de qualquer infinito. Por isso Lacan (19681969/2008) destaca que Pascal usa o plural ao falar em "vidas felizes" na frase "infinidade de vidas infinitamente felizes" 2 - não se trata da unidade de uma vida que se infinitiza na eternidade. Pascal pluraliza essas vidas em uma progressão sem fim e, a partir daí, pode tomar essas vidas como o infinito, que se opõe como vimos - à unidade. Assim, a incessante repetição - mais de Lacan do que de Pascal — da construção "infinidade de vidas infinitamente felizes" tem uma função precisa: de oposição à unidade. Vale ainda observarmos que a oposição não se limita àquela da vida isolada, mas também ao termo eternidade. Ao optar pela definição matemática de infinito em vez de eternidade, o filósofo promove o (in)quantificável em detrimento da dimensão (a)temporal, o que possibilita, por homologia, a formalização de seus postulados.

Objetar-se-ia que não necessariamente o jogador entrará na aposta. Mas é imprescindível recordarmos que a aposta aparece como um imperativo para Pascal: desde sempre o indivíduo está comprometido com a escolha. Apostar não é uma opção, pois a questão da existência de Deus se apresenta ao homem de modo inescapável. Depreende-se do fragmento Infinito nada que "é preciso apostar. Não é coisa que dependa da vontade, já estamos comprometidos nisso” (Pascal,

2 A tradução brasileira por nós consultada deixa escapar esse importante detalhe, utilizando o singular "vida" (Pascal, 1670/1961, p. 110). 
1670/1961, p. 110). Aqui, há a refutação de qualquer argumento que faça referência a outros possíveis, como a existência de um Deus não cristão, ou a isenção da escolha, pois há um impossível axiomático logo na entrada que se liga a esse comprometimento do sujeito, qual seja, a impossibilidade de não apostar. Há de se destacar também - na frase citada - que apostar não depende da vontade.

Assim, Pascal constrói uma refinada linha argumentativa, em que parte das premissas de que é preciso apostar e de que não se pode, por meio da razão, afirmar a existência de Deus. Tal cenário conduz à construção de um caminho que não é pela via do fornecimento de provas materiais ou racionais da existência divina. Se a aposta é necessária, nada se perde, pois a perda é condição para a aposta, sempre temos de ceder algo para entrar no jogo, sendo esse algo a vida. $\mathrm{Ou}$ seja, a perda é uma certeza, o ganho é uma incerteza. Entretanto, em se ganhando, tudo se ganha. Desse modo, é preciso apostar em sua existência, sem hesitação, visto que o jogador perderá aquilo que tem e, caso ganhe, ganhará tudo.

Tal conclusão é coerente com a escolha matematicamente viável, pois, se a aposta é entre a unidade da vida finita contra a infinidade de vidas infinitamente felizes, é esperado que se opte pelo infinito. Ainda que probabilisticamente houvesse uma grande maioria de chances da não existência de Deus, dever-se-ia apostar em sua existência, porque a unidade se anula perante o infinito.

Outra interessante refutação é à suposta objeção de que "é incerto ganhar e que é certo que se arrisca, e que a distância infinita que há entre a certeza do que se aventura, e a incerteza do que se ganhará, iguala o bem finito, que certamente se expõe, ao infinito, que é incerto", responde negativamente, afirmando que "todo jogador arrisca com certeza para ganhar com incerteza e, contudo, arrisca certamente o finito para ganhar incertamente o finito" (Pascal, 1670/1961, pp. 110-111). Há, de fato, a certeza do que se arrisca, mas o finito arriscado é desde sempre perdido se considerarmos que a aposta é um imperativo. Quanto ao infinito, não há garantias de ganho, mas é logicamente mais interessante apostar na existência, uma vez que o resultado da aposta só pode ser ganhar ou não ganhar: "vereis tanta certeza no ganho, e tanta nulidade naquilo que arriscaríeis, que reconhecereis, por fim, que apostastes numa coisa certa, infinita, pela qual nada destes" (Pascal, 1670/1961, pp. 111-112).

\section{A aposta em Lacan}

Lacan, no Seminário 16, comenta - de modo mais ou menos explícito - os pontos que destacamos do texto de Pascal.

Observa que a aposta de Pascal surgiu no mesmo período que uma modalidade de produção de saber que é o da ciência moderna. A aposta, entretanto, não repousa nesse saber, mas na palavra do Outro, "a palavra do Outro concebida como verdade” (Lacan, 1968-1969/2008, p. 168). Lembremos que o ponto de partida do 
filósofo é a admissão de que sobre Deus não sabemos, mas é possível hipotetizar sobre sua existência traçando uma linha homológica de raciocínio com aquele que nos leva à afirmação de que o infinito é verdadeiro, posto que é falsa a finitude dos números inteiros. Ou seja, Pascal suspende o saber e se apega à noção de verdade para sustentar suas proposições. A verdade está na palavra precisamente porque esta fala - não que fale sempre a verdade, ou que se diga como verdade. Por isso, a regra psicanalítica é a de que se fale, porque a fala é uma propriedade da verdade, e esta, por outro lado, não deriva de um saber estabelecido (como o saber religioso ou científico).

Para que se jogue o jogo nos termos de Pascal, denuncia Lacan, é preciso que o jogador assuma uma posição de indiferença, na medida em que não sabemos quem é Deus, tampouco se é. Apostar no infinito é ser indiferente a essa ignorância, a essa ausência de significantes que deem conta de dar consistência ao campo do saber.

Há um furo no discurso, que há em algum ponto um lugar onde não somos capazes de pôr o significante necessário para que todo o resto se sustente. Ele havia acreditado que o significante "Deus" poderia funcionar (Lacan, 1968-1969/2008, p. 173).

A nomeação tem aqui uma função que é a de tentar tapar a falta, falta inerente à produção da cadeia significante. A articulação entre significantes produz a emergência do sujeito, constitutivamente cindido desde a sua aparição, e o campo do Outro. A esse Outro é impossibilitado que dê consistência ao Um do discurso, pois é por definição vazado, e a tentativa de nomear fracassa reiteradamente.

O Outro não constitui um universo completo, e sim furado - pois falta um significante que permitiria dizer que é um conjunto totalizador de todos os significantes da linguagem ou, melhor dizendo, de uma determinada língua. Paradoxalmente ele não existe, pois por ser furado não tem consistência. No inconsciente, como discurso do Outro, sempre falta um significante último que daria um sentido último à vida. (Quinet, 2012, p. 30)

O Outro é um lugar, lugar de fala, de suposição. Que alguém fale a partir dessa posição significa que fala de um lugar que é estruturalmente furado. Falar pretendendo sustentar um saber, como em geral ocorre nos discursos científicos, quase sempre conduz ao tamponamento desse furo. A palavra médica que indicou que o pequeno G. era menino, e, portanto, precisava fazer a operação o quanto antes, funcionou como uma tentativa de tamponamento. Apostar em tal palavra é apostar na consistência do Outro e submeter-se obedientemente àquilo que se supõe ser seu desejo. Lacan comenta que a Graça divina, mencionada por Pascal, tem a mesma estrutura que a demanda, de que "Seja feita Tua Vontade" (Lacan, 1968-1969/2008, p. 145), que no primeiro patamar do grafo assume a forma da 
pergunta sobre "o que queres", que por sua vez se equilibra com "Eu te pergunto o que quero". Nesse sentido, "toda manifestação do desejo se inclina para um Seja feita a Tua Vontade" (Lacan, 1968-1969/2008, p. 122). A palavra médica funcionou para a paciente como uma resposta, e ela nada mais fez do que fazer conforme a vontade do Outro.

O discurso analítico se direciona para a saída desse circuito. Considerando que a aposta na existência do infinito nada mais é do que "a fé depositada no universo de discurso" (Lacan, 1968-1969/2008, p. 175), no fechamento desse universo, a aposta psicanalítica é outra ( $a$ ). Na sustentação da função do $a$, como causa de desejo, está a possibilidade de emergência do sujeito dividido, desejante e incompleto. Esse $a$ é a assumpção de que não há nome que represente o fechamento do discurso em torno de um saber, de que em todo ato de fala há equívoco, tropeço, vacilação.

\section{A aposta clínica}

Constatada a vacilação, iniciei alguns atendimentos com Ângela, sem o marido. Este, que ficou calado durante grande parte das entrevistas de avaliação, sempre se manifestava, quando o tema era a cirurgia, para reafirmar a palavra dada pela equipe médica: “é um menino, há de se operar". Na segunda entrevista, em um momento em que a mãe foi ao banheiro com G. para trocar-lhe a fralda, o pai revelou seu orgulho pelo aumento do pênis do garoto, outrora atrofiado, proporcionado pela ingestão de hormônios. Contou como se fosse um segredo - não o aumento do pênis, mas sua satisfação pela incipiente virilidade do filho - , manifestando um desejo que precisava ser ocultado da mãe. Tal ocultação, coerente com o desejo do pai, necessitava da conservação de determinada imagem para a mãe: a de que se tratava do sacrifício do casal, e não apenas dela, em nome de um saber médico. A confidência serviu como índice da posição por ele ocupada nessa decisão, em que era cômodo servir-se do discurso científico para velar algo de seu desejo. De modo que, aparentemente, não constituía uma questão para ele. Mesmo com minhas pontuações e indagações, mantinha-se impassível, justificando que a decisão era médica.

Lacan assevera que, para a compreensão da aposta, não basta questionarmos a existência de Deus, é preciso que se adicione à pergunta se o jogador é a favor ou contra. De forma tal que se abrem quatro horizontes: sei que Deus existe e sou a favor; sei que existe e sou contra; sei que não existe e sou contra; e sei que não existe e sou a favor. Assim, as sentenças "sei que Deus existe e aposto a favor" e "sei que não existe e aposto contra" advêm de pessoas seguras em suas posições, de pessoas que se deixam levar apenas por aquilo que sabem (Lacan, 1968-1969/2008, p. 147). O pai de G., nos parece, ocupava essa tranquila posição, e a palavra médica representava apenas a confirmação de suas expectativas e fantasias - fantasias que estruturavam sua verdade. Outra hipótese é a de que ele seria um entre os muitos pais (pères) sossegados (pépères) de que fala Lacan 
ao comentar a posição daqueles que, sabendo que Deus não existe, abrem mão do objeto $a$. Ao utilizar esse jogo de palavras, Lacan acentua a importância de certo tipo de relação com o pai e indica que é disso que se trata na aposta. Trata-se de fazer consistir um saber totalizante no campo do Outro, a suposição de um saber sem furos, um pai não castrado (Lacan, 1968-1969/2008, p. 146).

Ângela, inicialmente, também creditava alto valor à palavra dos médicos em seus enunciados. Durante as sessões, põe-se a associar. Revela, por exemplo, que, durante os primeiros meses de vida de G., tinha ainda a "esperança" de que os exames revelassem que fosse uma menina. Em certo momento, Ângela se descolou da certeza presente no discurso do pai e passou a admitir que tinha dúvidas sobre se o melhor seria realizar a operação ou deixar que o filho escolhesse na adolescência. Nessa dúvida, agora reconhecida como tal, estava a possibilidade de uma real decisão e de emergência do sujeito. Trazia-lhe sofrimento imaginar que G. pudesse "na adolescência ser vítima de bullying”, caso não operasse. Por outro lado, angustiava-lhe pensar sobre pelo que poderia passar a criança ao chegar à puberdade sem se reconhecer em um corpo de menino, culpando-a pelo resto da vida por tal decisão.

Ângela saiu da certeza para a incerteza. Apostar é já a incerteza fundamental. Entretanto, só há aposta quando há alguém que interrogue o apostador como $E u$. Esse que interroga (Pascal ou o analista) está aparentemente fora da aposta. Aposta-se não na existência de Deus, mas na existência do parceiro, que é aquele que sustenta o campo do Outro, ou seja, o Eu do saber. Aqui, estamos no campo do Seja feita a Tua Vontade, amparados por um saber. Para tanto, há de se renunciar ao $a$ para aceder a tal certeza. A outra escolha possível é aquela em que não se renuncia ao $a$ em sua função de desejo de saber, a aposta no $E u$ do gozo.

Pascal é categórico ao afirmar que a aposta não é uma questão de escolha, é imperativa, de tal modo que aquiescer à palavra médica é já decidir. Ângela se sabia comprometida com essa decisão e lhe pesava: o desejo de ter uma filha, a realização do luto da menina esperada, o medo de decidir egoisticamente, guiada por tal desejo, e o temor de ter de se haver com uma dívida vitalícia com o filho. A dívida em jogo é simbólica, e o temor apontou não para a castração real da criança, mas para uma atualização de sua própria castração. O que compromete o sujeito, entendamos, é a palavra:

A decisão é uma estrutura. É por estar a decisão reduzida a uma estrutura que podemos manipulá-la de maneira inteiramente científica. Só que, nesse nível da aposta, se vocês tiverem que tomar uma decisão, seja ela qual for, dentre duas que se proponham, se forem obrigados a fazê-lo de qualquer maneira, será apenas a partir do momento que forem interrogados dessa forma, e por Pascal, ou seja, a partir do momento que autorizarem a ser Eu nesse discurso. (Lacan, 1968-1969/2008, pp. 116-117) 
Para haver decisão, é necessária a existência de outro que interrogue o $E u$ em dado discurso; se não houver interrogação, não haverá uma decisão. O que se passou no caso de Ângela foi a ausência da interrogação pelos médicos e sua consequente desautorização como Eu. O discurso analítico foi o que instaurou a possibilidade de uma estrutura de decisão. A aposta não foi entre a criança ser um menino ou uma menina, mas apostar em decidir. Essa possibilidade de decidir implica que haja alguém que a interrogue como $E u$. Tal interrogação só se mantém no discurso analítico, que é também uma aposta, a aposta no sujeito suposto. O discurso médico, ao responder à questão da mãe, não deu condições de que ela pudesse de fato decidir.

A direção, entretanto, não foi no sentido de conduzir o sujeito a uma não decisão - isso seria fazer uso da psicanálise como uma verdade que se apresenta como tal. A verdade, nesse caso, seria a da manutenção da tensão. Essa tensão, uma vez que se aposte na fala transferencialmente direcionada ao analista, se manterá, e o analisante a cada momento se deparará com uma estrutura vazada, com a falta de sentido. É preciso que entendamos que não operar não é sinônimo de não decidir, mas de decidir pelo não. Da mesma forma, operar é decidir pelo sim. Ambas as posições têm o mesmo valor em psicanálise, pois tanto em uma quanto em outra há o desejo e o gozo como causa.

A psicanálise, desde Freud, acedeu a uma verdade sobre o inconsciente, e os psicanalistas devem sustentar as condições necessárias para a emergência da verdade. Entretanto, o discurso científico nos convoca insistentemente a sair de nossas posições para administrarmos um saber (Lacan, 1968-1969/2008, p. 167). $\mathrm{O}$ analista jamais deve ceder a tais investidas em sua clínica, pois, ao direcionar o paciente em suas decisões, realiza a junção entre saber e poder. E a psicanálise opera exatamente a partir dessa disjunção, pois o paciente é o ponto dessa disjunção (Lacan, 1968-1969/2008, p. 290). Recordemos a célebre frase contida em $A$ direção do tratamento e os princípios do seu poder:

Nisso estava o princípio de seu poder, no que este não se distinguia da sugestão, mas também que esse poder só lhe dava a solução do problema na condição de não se servir dele, pois era então que assumia todo o seu desenvolvimento de transferência. (Lacan, 1958/1998, p. 603)

O analista não se serve do poder a ele conferido. No choro de Ângela, ao falar sobre a cirurgia, estava o ponto de disjunção, o indicador de que o saber médico não apaziguou os gritos do sujeito. Falava do filho, mas também falava de si, de que vinha se dando conta de que se esquecera de si nos últimos tempos. Na última consulta antes da operação, disse peremptoriamente que não mudaria de ideia; 
entretanto, quando questionada, vacilou, chorou silenciosamente. Continuou associando, sem voltar ao assunto.

No atendimento posterior à data agendada da cirurgia, Ângela revelou que optou por adiar, um dia antes. Disse que precisava sentir-se mais preparada. Falou que desde a primeira consulta até o momento sentia-se menos angustiada. Encaminhei para que fizesse psicoterapia na UBS, visto que não poderia dar prosseguimento aos atendimentos psicanalíticos, posto que o público de atendimento do CAPSij são crianças e adolescentes.

Em vez da operação de redesignação, o que se operou foi um deslocamento da posição do sujeito na estrutura discursiva. A palavra médica foi alçada ao estatuto de saber absoluto acerca da verdade sobre a criança. Em um primeiro momento, esse absoluto apresentou-se sob a forma de um enigma e soterrou qualquer possibilidade de investimento materno no primeiro semestre de vida de G., período em que a mãe entrou em depressão e o tio assumiu os cuidados da criança. $\mathrm{O}$ fato de G. ter usado roupas de menina durante os primeiros meses também diz de um desejo abafado pela palavra, que suspendeu a definição de seu gênero - considerando, é claro, que os pais tinham condições financeiras de refazer o enxoval. Em um segundo momento, a palavra médica se impõe, trazendo a verdade que suprime, de vez, a manifestação do desejo de Ângela: “é um menino". A partir daí, uma série de medidas são tomadas no pequeno corpo, como a introdução de altas doses de testosterona e intervenções médicas para o aumento do pênis.

"É um menino!"; logo, é preciso suturar o mais depressa possível esse pequeno empecilho - empecilho real —, que desvela a ficção que acompanha os exames genéticos. Mais do que a criança, o sujeito suturado, no caso, seria Ângela. Como já indicara Lacan (1966/1998, p. 875) em A ciência e a verdade, quando afirmou que a ciência fracassa reiteradamente em suas tentativas de suturar o sujeito. A tentativa malograda de sutura por parte da ciência seria o rigoroso esforço na produção do apagamento da Spaltung (divisão subjetiva). Tal esforço, indica ainda Lacan (1966/1998, p. 875), é aquilo que define a ciência como correlato antinômico do conceito de sujeito. Assim é definida por se caracterizar pela profusão de respostas, que são marcadas por um não-querer-saber-nada da verdade como causa.

Se houve algo em jogo no discurso que se instalou, foi a castração do desejo materno e o fracasso da sutura. Desejo que seria anulado pela promessa implícita no discurso médico - de que haveria um garoto infinitamente feliz em seu futuro. A aposta é feita sobre um discurso que está ligado a Deus, ou seja, uma promessa. Entretanto, o discurso da promessa não é de uma promessa feita por Deus, mas imputada a ele (Lacan, 1968-1969/2008, p. 141). Por quem? Por aquele que interroga o Eu. Ou seja, é preciso que ela seja enunciada, a promessa não está dada. Pascal é quem diz: "vocês estão comprometidos". Do mesmo modo, a mãe de G. escutou dos médicos que era possível fazer uma operação de redesignação 
sexual, comprometendo-a instantaneamente com a decisão.

Deslocar-se ante tal estrutura discursiva é visualizar os furos que comportam tal promessa; é aproximar-se do real da ausência de garantias, e Ângela o fez ao projetar que talvez o futuro de G. não seja infinitamente feliz uma vez operado, tampouco o será se não operar. A única certeza é a de que o sujeito terá de se haver com sua condição, e ela, com a decisão tomada. Uma vez que se entra na aposta, algo está para sempre perdido, adverte Pascal. E quando, associando livremente, equivocando, tropeçando e nomeando seu desejo, Ângela se dá conta de que não há certezas de ganho, ela passa a vacilar. Coloca em dúvida a decisão, antes resoluta, e sua vacilação se transforma em ato ao impedir a cirurgia. Aqui há uma mudança discursiva, outrora Ângela dava consistência ao Outro, e ao ser indagada a partir de um discurso sem palavras, de silêncios, cortes e citações, pode deslocar sua aposta para um campo de incertezas: o discurso analítico - se não podemos, por um lado, afirmar que houve uma análise, por outro, é correto dizer que se operaram giros discursivos. Aqui, há um sujeito colocado em questão, ou seja, na dimensão do incerto, um sujeito que não sabe e, portanto, vacila. Que o sujeito esteja comprometido não significa que seja com a aposta na consistência, mas talvez comprometido com o $a$, falha no saber, objeto causa. Causa do desejo de saber.

\section{Referências bibliográficas}

Lacan, J. (1958/1998). A direção do tratamento e os princípios de seu poder. In J. Lacan. Escritos (pp. 591-652). (Vera Ribeiro, Trad.). Rio de Janeiro: Jorge Zahar. Lacan, J. (1966/1998). A ciência e a verdade. In J. Lacan. Escritos (pp. 869-892).

(Vera Ribeiro, Trad.). Rio de Janeiro: Jorge Zahar.

Lacan, J. (1968-1969/2008). O seminário, livro 16: de um Outro ao outro. (Vera

Ribeiro, Trad.). Rio de Janeiro: Jorge Zahar.

Pascal, B. (1670/1961). Pensamentos. (Sérgio Milliet, Trad.). São Paulo: Difusão Europeia do Livro.

Quinet, A. (2012). Os outros em Lacan. Rio de Janeiro: Jorge Zahar.

Recebido: 15/10/2017

Aprovado: 15/01/2018 